\title{
Phenolic Profile and Antioxidant Activity of Crude Extracts from Microalgae and Cyanobacteria Strains
}

\author{
Idaira Jerez-Martel, ${ }^{1}$ Sara García-Poza, ${ }^{1}$ Gara Rodríguez-Martel, ${ }^{1}$ Milagros Rico,, \\ Cristina Afonso-Olivares, ${ }^{2}$ and Juan Luis Gómez-Pinchetti ${ }^{3}$ \\ ${ }^{1}$ Grupo QUIMA, Instituto de Oceanografía y Cambio Global, Universidad de Las Palmas de Gran Canaria, \\ Campus de Tafira, Las Palmas de Gran Canaria, 35017 Canary Islands, Spain \\ ${ }^{2}$ Instituto Universitario de Estudios Ambientales y Recursos Naturales (i-UNAT), Universidad de Las Palmas de Gran Canaria, \\ Campus de Tafira, Las Palmas de Gran Canaria, 35017 Canary Islands, Spain \\ ${ }^{3}$ Banco Español de Algas, Instituto de Oceanografía y Cambio Global, Universidad de Las Palmas de Gran Canaria, \\ Muelle de Taliarte $s / n$, Telde, 35214 Canary Islands, Spain
}

Correspondence should be addressed to Milagros Rico; milagros.ricosantos@ulpgc.es

Received 11 January 2017; Accepted 16 March 2017; Published 30 March 2017

Academic Editor: José M. Hernández-Hierro

Copyright (C) 2017 Idaira Jerez-Martel et al. This is an open access article distributed under the Creative Commons Attribution License, which permits unrestricted use, distribution, and reproduction in any medium, provided the original work is properly cited.

Aqueous and methanolic extracts of several microalgae (Ankistrodesmus sp., Spirogyra sp., Euglena cantabrica, and Caespitella pascheri) and cyanobacteria (Nostoc sp., Nostoc commune, Nodularia spumigena, Leptolyngbya protospira, Phormidiochaete sp., and Arthrospira platensis) were screened for their radical scavenging activity against the stable radical 1,1-diphenyl-2-picrylhydrazyl. Despite the fact that water was a more efficient solvent to extract greater amount of extractable substances, it seems that methanol was more efficient to extract a selected group of compounds with a higher antioxidant activity. In addition, the identification of 4 simple phenolics (gallic, syringic, protocatechuic, and chlorogenic acids) and the flavonoids (+) catechin and (-) epicatechin was carried out by using reverse phase high performance liquid chromatography. The strain Euglena cantabrica showed the highest concentration of phenolic compounds, particularly gallic and protocatechuic acids (5.87 and $2.97 \mathrm{mg}$ per gram of dried biomass, resp.). Aqueous and methanolic extracts of microalgae Euglena cantabrica also exhibited the highest antioxidant activity, probably due to the presence of the high contents of phenolics.

\section{Introduction}

In living systems under stress conditions, the excessive generation of hydroxyl radical $\left(\mathrm{OH}^{*}\right)$ and other highly reactive oxygen species (ROS) produces oxidative damage through the reaction of these species with many biomolecules including DNA [1]. Several studies on pharmacological research have evidenced that oxidative stress and increased amounts of free radicals are features of chronic diseases including cancer [2], aging, and neurodegenerative diseases such as Alzheimer's and Parkinson's $[3,4]$ and cardiovascular diseases such as atherosclerosis [5]. Phenolic compounds are secondary metabolites widely distributed in plants with wellknown health benefits $[6,7]$. These compounds are described as radical scavengers because they are donors of hydrogen atoms or electrons, producing stable radical intermediates. They can also inhibit iron-mediated oxyradical formation to prevent various processes of oxidative stress considering the origin of the above cited diseases [8]. Epidemiological studies have confirmed that consumption of diets rich in phenolic compounds may prevent the onset of many degenerative diseases $[1,9]$.

On the other hand, lipid oxidation is the greater cause of food quality deterioration [10]. Several reports have been focused on the enrichment of food products with seaweed extracts to evaluate their preservative properties and/or nutritional benefits [11, 12]. Extruded maize product enriched with red seaweed Porphyra columbina showed higher total phenolic content and antioxidant capacity than the extruded maize without seaweed [13]. Addition of edible seaweeds, 
Sea Spaghetti (Himanthalia elongata), Wakame (Undaria pinnatifida), and Nori (Porphyra umbilicalis) to low-salt meat emulsion model systems, enriched the meat samples with soluble polyphenolic compounds thereby enhancing the antioxidant capacity of the systems [14]. Incorporation of four different seaweed extracts (cochayuyo, sea lettuce, ulte, and red luche) as part of the covering liquids of canned Atlantic salmon (Salmo salar) provided advantages in the preservation of the fish samples [15]. Rodríguez De Marco et al. [16] studied the effect of the incorporation of spirulina on nutritional quality of dried pasta concluding that these samples of pasta exhibited higher phenolic content and antioxidant capacity compared to control sample.

Despite the reported antioxidant properties of the phenolic compounds and the potential of microalgae and cyanobacteria as sources of these compounds [17], few studies have focused on their identification and quantification in microalgae [18-20] and on the role played by phenolics in microalgae defense mechanisms against high ROS levels [21-23]. Reports on the evaluation of antioxidant activity of microalgae and cyanobacteria extracts $[24,25]$ have also concluded that a high number of microalgal species produce a wide range of antioxidants, including carotenoids, polyunsaturated fatty acids, polysaccharides, or mycosporine-like amino acids (MAAs). These studies generally apply the Folin-Ciocalteu test to quantify the antioxidant capacity of samples from micro- or macroalgal cells without focusing on the identification of specific phenolic components, probably due to the assumed hypothesis that phenolic compounds are only terrestrial lignin-derivatives [21, 26, 27]. In fact, Waterman and Mole [28] defined polyphenolic secondary metabolites as compounds with a wide diversity of chemical structures, which are present in terrestrial plants and aquatic macrophytes (excluding microalgae).

However, pioneer papers show that microalgae and cyanobacteria also contain phenolic and cinnamic acid derivatives at $\mu \mathrm{g}$ levels on a dry weight basis $[29,30]$ and evidences for microalgae polyphenols synthesis are clear [21-23]. Therefore, it is necessary to improve accurate methodologies to detect and quantify phenolics in microalgae and cyanobacteria, which help to explain the role played by these compounds $[22,31]$. The increased demand for healthy foods might then use a nontraditional alternative source of natural antioxidants and other ingredients, with potential benefits for consumers, based on microalgae and cyanobacteria [17, 32, 33].

The main objective of this work was to determine the antioxidant activity of extracts obtained from several microalgae and cyanobacteria strains with regard to their potential uses. Moreover, 6 phenolic compounds (gallic acid, $(+)$ catechin, (-) epicatechin, syringic acid, protocatechuic acid, and chlorogenic acid) have been identified and quantified in the extracts by reverse phase high performance liquid chromatography (RP-HPLC). These compounds were selected because several reports have demonstrated that they are widely distributed in nature: algae [23,34], common edible Mediterranean plants [35], and fruits and vegetables [36]. According to this, different strains of microalgae and cyanobacteria, most of them are bioprospected at the Canarian Archipelago and mainland Spain, identified, and deposited at the culture collection of the Spanish Bank of Algae (http://www.bea.marinebiotechnology.org), are being characterized to identify possible metabolites with interest for biotechnological applications.

\section{Materials and Methods}

2.1. Chemicals. Methanol (HPLC grade) and formic acid (analytical quality) were from Panreac (Barcelona, Spain). Water used through the entire study was purified on a Milli-Q system from Millipore (Bedford, MA, USA). The radical 1,1diphenyl-2-picrylhydrazyl (DPPH) was from Sigma-Aldrich Chemie (Steinheim, Germany). Phenolic standards, gallic acid (GA), protocatechuic acid (PA), (-) epicatechin (E), chlorogenic acid (CA), syringic acid (SA), $(+)$ catechin $(\mathrm{C})$, butylated hydroxyanisole (BHA), and butylated hydroxytoluene (BHT), were purchased from Sigma-Aldrich Chemie (Steinheim).

The cartridges for solid phase extraction (SPE) were Chromabond Easy containing $500 \mathrm{mg}$ of polar modified polystyrene divinylbenzene (particle size $93 \mu \mathrm{m}$ ) from MachereyNagel.

2.2. Algal Strains and Culture Conditions. Microalgae and cyanobacteria clonal strains were provided by the culture collection at the Spanish Bank of Algae (Table 1). Cultures were scaled up to 5-L flasks, under controlled conditions, at a light intensity of $100 \mu \mathrm{mol}$ photons $\mathrm{m}^{-2} \mathrm{~s}^{-1}$ with a photoperiod of $16: 8(\mathrm{~L}: \mathrm{D})$, temperature at $23 \pm 2^{\circ} \mathrm{C}$, and continuous aeration supplied with $\mathrm{CO}_{2}$ pulse addition at a rate of 1 min every hour. Biomass samples were harvested, concentrated, frozen at $-80^{\circ} \mathrm{C}$, and freeze-dried (6.5 L Labconco, USA) before extractions were carried out. For Arthrospira platensis (BEA 0016B) a second biomass sample was obtained, under outdoor conditions, in a modified culture medium enriched with urea (AA).

2.3. Preparation of Extracts for Antioxidant Activity Determination. Freeze-dried microalgae and cyanobacteria biomass ( $25 \mathrm{mg}$ ) were extracted with $2 \mathrm{~mL}$ of solvent (methanol and water were separately tested) for $40 \mathrm{~min}$ at room temperature by using a vortex stirrer (IKA/GENIUS 3). After centrifugation at $3000 \mathrm{rpm}$ for $10 \mathrm{~min}$ (centrifuge HERAEUS Fresco 17), the supernatant was collected and evaporated to dryness in a rotary vacuum evaporator (Eppendorf, Concentrator Plus 5305). The amount of extractable substances was expressed as a percentage by weight of the freeze-dried biomass.

The extractions were performed in triplicate and concentrates were dissolved in methanol $\left(10 \mathrm{mg} \mathrm{m}^{-1}\right)$ to test the antioxidant capacity (in triplicate). Strains showing no antioxidant activity were also prepared at $40 \mathrm{mg} \mathrm{mL}^{-1}$ (Nostoc commune, Arthrospira platensis, and Caespitella pascheri). In addition, Euglena cantabrica concentrate was also dissolved at $1 \mathrm{mg} \mathrm{mL}^{-1}$ and $5 \mathrm{mg} \mathrm{mL}^{-1}$.

Methanol solutions of pure phenolic compounds were used as standards and prepared as follows: BHA and BHT at $1 \mathrm{mg} \mathrm{mL}^{-1}$ and $0.1 \mathrm{mg} \mathrm{mL}^{-1}$ and GA, C, E, SA, PA, and CA at $0.1 \mathrm{mg} \mathrm{mL}^{-1}$. 
TABLE 1: Microalgae and cyanobacteria strains assayed, indicating origin and culture medium for biomass production.

\begin{tabular}{|c|c|c|c|c|}
\hline BEA code & Strain & Class & Culture medium & Geographical origin \\
\hline BEA 0016B & Arthrospira platensis & Cyanophyceae & Zarrouk $^{\mathrm{a}}$ & Chad, Lake Chad \\
\hline BEA 0024B & Nostoc commune & Cyanophyceae & BG-11 & $\begin{array}{c}\text { Spain, Canary Islands, Gran Canaria. On } \\
\text { a trunk of Phoenix canariensis }\end{array}$ \\
\hline BEA 0661B & Leptolyngbya protospira & Cyanophyceae & BG-11 & $\begin{array}{c}\text { Spain, Canary Islands, Gran Canaria. } \\
\text { Güigüí Ravine }\end{array}$ \\
\hline BEA 0762B & Phormidiochaete sp. & Cyanophyceae & BG-11 & Spain, Galicia, Ourense. Las Burgas \\
\hline BEA 0854B & Nodularia spumigena & Cyanophyceae & BG-11 & Spain, Vizcaya, Vitoria. Añana saltworks \\
\hline BEA 1052B & Nostoc sp. & Cyanophyceae & BG-11 & $\begin{array}{l}\text { Spain, Canary Islands, Gran Canaria. } \\
\text { Tirajana, Hondo ravine }\end{array}$ \\
\hline BEA 0149B & Caespitella pascheri & Chlorophyceae & $\mathrm{BBM}^{\mathrm{b}}$ & $\begin{array}{l}\text { Spain, Canary Islands, Gran Canaria. } \\
\text { Guayadeque ravine }\end{array}$ \\
\hline BEA 0536B & Ankistrodesmus sp. & Chlorophyceae & BG-11 & $\begin{array}{c}\text { Spain, Canary Islands, La Gomera. Las } \\
\text { Rosas reservoir }\end{array}$ \\
\hline BEA 0937B & Euglena cantabrica & Euglenophyceae & $\mathrm{BBM}^{\mathrm{b}}$ & $\begin{array}{l}\text { Spain, Canary Islands, Gran Canaria. } \\
\text { Charca de Maspalomas }\end{array}$ \\
\hline BEA 0666B & Spirogyra sp. & Zygnematophyceae & BG-11 & $\begin{array}{c}\text { Spain, Canary Islands, Gran Canaria. } \\
\text { Azuaje ravine. }\end{array}$ \\
\hline
\end{tabular}

${ }^{a}$ A second biomass sample of BEA 0016B (AA) Arthrospira platensis was obtained from a modified Zarrouk culture medium enriched with urea.

${ }^{\mathrm{b}} \mathrm{BBM}$ : Bold's basal medium including vitamins.

2.4. Free Radical Scavenging Activity on DPPH. The sample solution $(20 \mu \mathrm{L}$ of pure phenolic compound solutions or extracts prepared from algal samples) and $1 \mathrm{~mL}$ of $\mathrm{DPPH}$ $(0.1 \mathrm{mM})$ were mixed. After $20 \mathrm{~min}$ incubation at $23^{\circ} \mathrm{C}$ in darkness, the inhibition of the DPPH was monitored against a methanol blank. The ability of the samples to scavenge $\mathrm{DPPH}$ radical was evaluated by measuring the decrease in absorbance (Abs) at $515 \mathrm{~nm}$ using a Shimadzu $1700 \mathrm{UV}$-Vis spectrophotometer. The decolorization percentage of DPPH was calculated by the following equation: $\mathrm{RSA}=100 \times[1$ - (Abs of DPPH solution mixed with the sample)/(Abs of DPPH solution)] and half-life time $(t 1 / 2)$ was calculated as the time required for reducing initial concentration of DPPH by $50 \%$. All the tests were performed in triplicate and the results were averaged.

2.5. Preparation of Extracts by Solid Phase Extraction (SPE) for the Phenolic Profile Analysis by RP-HPLC. Freeze-dried material $(0.6 \mathrm{~g})$ was mixed with Milli-Q water $(60 \mathrm{~mL})$ for $1 \mathrm{~h}$ at room temperature by using a multipoint magnetic stirrer (ANM-10006, Paris, France). The extract was filtered for removal of solid particles and after centrifugation at $3500 \mathrm{rpm}$ for $10 \mathrm{~min}$ (ALC-4232), the supernatant was collected and hydrolysed at room temperature by addition of $\mathrm{HCl}\left(2 \mathrm{~mol} \mathrm{~L}^{-1}\right)$. After $60 \mathrm{~min}$, hydrolysates were purified using solid phase extraction (SPE) according to a previously reported method with several modifications [22].

The SPE cartridge was equilibrated with $3 \mathrm{~mL}$ of methanol followed by $3 \mathrm{~mL}$ of Milli-Q water and samples were loaded into cartridges at a flow of $2.5 \mathrm{~mL} \mathrm{~min}^{-1}$. The cartridge was rinsed with $2 \mathrm{~mL}$ of aqueous methanol solution (5\%) and the analytes were recovered by washing the cartridge with $4 \mathrm{~mL}$ of methanol. After completion of eluent evaporation, methanol was added $(300 \mu \mathrm{L})$ to the residue and the resulting solution was filtered using a $45 \mu \mathrm{m}$ nylon syringe filter to be injected into the HPLC system. In these conditions, it was impossible to calculate concentrations for GA and PA that fall outside the range of the calibration curve in Euglena cantabrica extract. Therefore, $20 \mu \mathrm{L}$ of the filtered solution obtained from this strain was also diluted with methanol making a total volume of $1 \mathrm{~mL}$.

2.6. Determination of the Phenolic Profile by RP-HPLC. Chromatographic analysis was performed on a Liquid Chromatography Varian system, equipped with a ternary pump, an autosampler, and a diode array detector (DAD), connected to a computer installed Star software. The column $(250 \mathrm{~mm} \times 4.6 \mathrm{~mm}, 5 \mu \mathrm{m})$ and the guard column $(10 \mathrm{~mm} \times$ $4.6 \mathrm{~mm}, 5 \mu \mathrm{m}$ ) were reverse phase Pursuit XRs C18 (Varian, Barcelona). Two mobile phases were used: eluent A was water enriched with $0.1 \%$ formic acid and eluent B was methanol. The column operated at a flow rate of $1.0 \mathrm{~mL} \mathrm{~min}^{-1}$, and $20 \mu \mathrm{L}$ of each sample was separately injected. The applied elution conditions began with $15 \% \mathrm{~B}$ and increased up to $40 \% \mathrm{~B}$ in $13 \mathrm{~min}$; it was then changed for $1 \mathrm{~min}$ to $40 \% \mathrm{~B}$ and a linear gradient from $40 \%$ to $30 \%$ B for $1 \mathrm{~min}$. After that, it was returned to $40 \% \mathrm{~B}$ for $1 \mathrm{~min}$ and kept isocratic for $2 \mathrm{~min}$. Finally, it was returned for $3 \mathrm{~min}$ to its initial condition in order to equilibrate pressures. Each standard phenolic compound was individually injected to check the retention times (RT). Monitoring was set at $270 \mathrm{~nm}$ (GA, PA, $\mathrm{C}, \mathrm{E}$, and SA) and $324 \mathrm{~nm}$ (CA) for quantification. Calibration curves were prepared in the range of concentrations between 1 and $100 \mu \mathrm{g} \mathrm{mL}^{-1}$ for determination of C, E, SA, and CA and between 1 and $800 \mu \mathrm{g} \mathrm{mL}^{-1}$ to quantify GA and PA. The linearity was estimated by linear regression analysis applying the least square method. Limits of detection (LOD) and limits of quantification (LOQ) were determined based on signal-tonoise ratio at 3 and 10 , respectively. 
TABLE 2: Extraction yields in methanol and water, expressed as a percentage by weight of the freeze-dried biomass.

\begin{tabular}{lcc}
\hline & Wethanol & Water \\
\hline Cyanobacteria & & 31.9 \\
Nostoc commune & 5.86 & 34.0 \\
Nostoc sp. & 7.03 & 26.4 \\
Leptolyngbya protospira & 8.30 & 63.2 \\
Nodularia spumigena & 20.3 & 14.4 \\
Phormidiochaete sp. & 6.43 \\
Arthrospira platensis (AA) & 21.8 & 57.2 \\
Arthrospira platensis & 28.1 & 54.6 \\
Microalgae & & 25.7 \\
Euglena cantabrica & 57.9 \\
Caespitella pascheri & 16.3 \\
Spirogyra sp. & 12.8 \\
Ankistrodesmus sp. & 18.3 \\
\hline
\end{tabular}

\section{Results and Discussion}

3.1. Extraction Yields for Microalgae and Cyanobacteria. Yields for the assayed microalgae and cyanobacteria extractions were determined and presented in Table 2. The results obtained in the present study are consistent with previous reports, which have shown that the extraction yield is strongly dependent on the solvent polarity and extracts prepared with polar solvents gave the highest percentages of extractable substances $[37,38]$. As can be observed in Table 2, water increased the efficiency of the extractions with two exceptions: extracts obtained from Euglena cantabrica and Caespitella pascheri showed the highest yield when methanol was used as solvent.

The highest yields were found in cyanobacteria strains Nodularia spumigena and Arthrospira platensis cultivated in the presence (AA) and absence of urea (63.2\%, 57.2\%, and $54.6 \%$, resp.) and microalgae Euglena cantabrica (57.9\%).

3.2. Free Radical Scavenging Activity on DPPH. From the results presented in Table 3, the cyanobacteria Nostoc commune and Arthrospira platensis did not inhibit DPPH radical, even at the highest tested concentration of $40 \mathrm{mg} \mathrm{mL}^{-1}$, while eukaryotic Caespitella pascheri showed activity only when the extract was prepared at this higher concentration. The remaining cyanobacteria exhibited low values of capacity to scavenge free radical DPPH that ranged from $7.65 \%$ (Leptolyngbya protospira) to $27.89 \%$ (Nostoc sp.). Extracts from microalgae Euglena cantabrica displayed considerably stronger relative radical scavenging efficiencies than the other strains $(100 \%$ inhibition when extracts were prepared with water and methanol at concentrations $10 \mathrm{mg} \mathrm{mL}^{-1}$ and $5 \mathrm{mg}$ $\mathrm{mL}^{-1}$ ) with a half-life $(t 1 / 2)$ lower than $2.1 \mathrm{~s}$ followed by methanolic extract of Spirogyra sp. (61.56\%) with a $t 1 / 2$ of $202 \mathrm{~s}$.

Our results demonstrated that cyanobacteria strains (Nostoc sp., Leptolyngbya protospira, Nodularia spumigena, and Phormidiochaete sp.) and microalgae (Euglena cantabrica, Caespitella pascheri, Spirogyra sp., and Ankistrodesmus sp.) showed DPPH scavenging capacity when the samples
TABLE 3: Relative radical scavenging activity (RSA) of samples expressed as \% inhibition \pm standard deviation of three measurements and half-life $(t 1 / 2)$ in seconds.

\begin{tabular}{|c|c|c|}
\hline & $\begin{array}{l}\text { Methanol } \\
\text { RSA }(t 1 / 2)\end{array}$ & $\begin{array}{c}\text { Water } \\
\text { RSA }(t 1 / 2)\end{array}$ \\
\hline \multicolumn{3}{|l|}{ Cyanobacteria } \\
\hline Nostoc commune $e^{\mathrm{a}, \mathrm{b}}$ & - & - \\
\hline Nostoc sp. ${ }^{\mathrm{b}}$ & $27.89 \pm 0.01$ & - \\
\hline Leptolyngbya protospira ${ }^{\mathrm{b}}$ & $7.65 \pm 0.01$ & - \\
\hline Nodularia spumigena ${ }^{\mathrm{b}}$ & $13.02 \pm 0.02$ & - \\
\hline Phormidiochaete sp. ${ }^{\mathrm{b}}$ & $14.59 \pm 0.01$ & $9.14 \pm 0.02$ \\
\hline Arthrospira platensis (AA) ${ }^{\mathrm{a}, \mathrm{b}}$ & - & - \\
\hline Arthrospira platensis ${ }^{\mathrm{a}, \mathrm{b}}$ & - & - \\
\hline \multicolumn{3}{|l|}{ Microalgae } \\
\hline Euglena cantabrica $^{\mathrm{b}}$ & $100 \pm 0(<2)$ & $\begin{array}{c}100 \pm 0 \\
(<2)\end{array}$ \\
\hline Euglena cantabrica ${ }^{c}$ & $100 \pm 0(2.1 \pm 0)$ & $\begin{array}{l}100 \pm 0 \\
(2.1 \pm 0)\end{array}$ \\
\hline Euglena cantabrica $^{\mathrm{d}}$ & $71 \pm 0.4(4 \pm 0)$ & $48.9 \pm 0.2$ \\
\hline Caespitella pascheri ${ }^{\mathrm{a}}$ & $26.3 \pm 0.2$ & - \\
\hline Caespitella pascheri ${ }^{\mathrm{b}}$ & - & - \\
\hline Spirogyra sp. ${ }^{\mathrm{b}}$ & $\begin{array}{c}61.56 \pm 0.04 \\
(202 \pm 3)\end{array}$ & $\begin{array}{c}43.37 \pm \\
0.01\end{array}$ \\
\hline Ankistrodesmus sp. ${ }^{\mathrm{b}}$ & $29.43 \pm 0.00$ & $8.3 \pm 0.0$ \\
\hline \multicolumn{3}{|l|}{ Synthetic preservatives } \\
\hline $\mathrm{BHA}^{\mathrm{d}}$ & $91 \pm 2(130 \pm 9)$ & $\mathrm{NE}$ \\
\hline $\mathrm{BHT}^{\mathrm{d}}$ & $26 \pm 2$ & $\mathrm{NE}$ \\
\hline
\end{tabular}

${ }^{\mathrm{a}}$ Samples prepared at $40 \mathrm{mg} \mathrm{mL}^{-1}$.

${ }^{\mathrm{b}}$ Samples prepared at $10 \mathrm{mg} \mathrm{mL}^{-1}$.

${ }^{\mathrm{c}}$ Samples prepared at $5 \mathrm{mg} \mathrm{mL}^{-1}$.

${ }^{\mathrm{d}}$ Samples prepared at $1 \mathrm{mg} \mathrm{mL}^{-1}$.

- means activity not detected.

NE: not evaluated.

were prepared at a higher concentration than the solutions of the standards BHA and BHT, the most widely used 
TABLE 4: Methodological data for quantitative determination of phenolic standards analysed by RP-HPLC.

\begin{tabular}{lcccc}
\hline Phenolic compound & LOD $^{\mathrm{a}}\left(\mu \mathrm{g} \mathrm{mL}^{-1}\right)$ & $\mathrm{LOQ}^{\mathrm{a}}\left(\mu \mathrm{g} \mathrm{mL}^{-1}\right)$ & Regression equation & Correlation coefficient $(r)$ \\
\hline GA & 0.024261 & 0.080868 & $y=293189 x-420948$ & 0.9990 \\
PA & 0.014679 & 0.048930 & $y=234664 x-98186$ & 0.9995 \\
C & 0.113697 & 0.378993 & $y=49026 x-164952$ & 0.9997 \\
CA & 0.131857 & 0.439524 & $y=287357 x-26773$ & 0.9981 \\
E & 0.128127 & 0.427090 & $y=50853 x-377965$ & 0.9982 \\
SA & 0.027729 & 0.092429 & $y=288245 x-7411113$ & 0.9973 \\
\hline
\end{tabular}

${ }^{a}$ Detection limits were calculated as signal-to-noise ratio of six determinations.

TABLE 5: Phenolic compounds detected in the samples in $\mu \mathrm{g}$ per gram of freeze-dried algal biomass.

\begin{tabular}{|c|c|c|c|c|c|c|}
\hline & \multicolumn{6}{|c|}{ Phenolic compound } \\
\hline & GA & PA & $\mathrm{C}$ & $\mathrm{CA}$ & $\mathrm{E}$ & SA \\
\hline \multicolumn{7}{|c|}{ Cyanobacteria } \\
\hline Nostoc commune & 71 & - & - & 2.16 & - & - \\
\hline \multicolumn{7}{|c|}{ Microalgae } \\
\hline Euglena cantabrica & 5,872 & 2,970 & 71.4 & 78 & 7.1 & - \\
\hline Spirogyra sp. & 91.4 & - & - & - & - & - \\
\hline Ankistrodesmus sp. & - & 25.4 & - & - & - & - \\
\hline
\end{tabular}

-: not detected.

food synthetic preservatives. At the same concentration of $1 \mathrm{mg} \mathrm{mL}^{-1}$, Euglena cantabrica gave higher radical scavenging activity $(71 \%)$ than BHT (26\%) and lower activity and halflife (4s) than BHA ( $91 \%$ with a half-life of $130 \mathrm{~s}$ ). Our results align well with Rodríguez-García and Guil-Guerrero [33] who determined the antioxidant activity of the microalgal ethanolic extracts of Porphyridium cruentum, Phaeodactylum tricornutum and Chlorella vulgaris by means of the $\beta$ carotene-linoleate model system, where the activity of $C$. vulgaris extract was higher than those obtained for the other microalgal extracts tested and for the synthetics BHA and BHT.

The relative RSA of the pure standards (at concentration $0.1 \mathrm{mg} \mathrm{mL}^{-1}$ ) was as follows: gallic acid: $94 \%(t 1 / 2120 \mathrm{~s})$; syringic acid: $38.1 \%$; $(+)$ catechin: $30.5 \%$; $(-)$ epicatechin: $31.8 \%$; protocatechuic acid: $26.2 \%$; chlorogenic acid: $26 \%$; and BHA: $18.1 \%$ and BHT did not show activity (Figure 1).

Despite the fact that water was more efficient solvent to extract greater amount of extractable substances, it seems that methanol was more efficient to extract a selected group of compounds with a higher antioxidant activity (Table 3). These results corroborate well with earlier reports focused on the extraction of nine microalgae strains with different solvents (ethanol, aqueous ethanol, and water) to study the capacity of extracts to scavenge DPPH radical [39]. The authors concluded that the aqueous extract of all the tested strains exhibited lower scavenging activities than the alcoholic extracts. These same results were observed by Herrero et al. [19] optimizing the extraction of antioxidants from the chlorophyte Dunaliella salina. However, Rao et al. [25] reported that there was no major difference in the antioxidant activity of the green colonial microalga Botryococcus braunii extracted by different solvents (acetone, methanol, ethanol, chloroform/methanol $(1: 1$ and $2: 1, \mathrm{v} / \mathrm{v})$, petroleum ether, hexane, and ethyl acetate).

3.3. Phenolic Profile by RP-HPLC. Phenolic compounds were identified by comparing retention times (RT) with those of standards and by extensive UV-Vis spectral analysis. An internal standard was used to avoid the matrix effect and to improve the precision of quantitative analysis. GA (RT: $6.15 \mathrm{~min}$ ), PA (RT: $9.85 \mathrm{~min}$ ), C (RT: $11.45 \mathrm{~min}), \mathrm{CA}$ (RT: $12.97 \mathrm{~min}), \mathrm{E}(\mathrm{RT}: 14.97 \mathrm{~min})$, and SA (RT: $15.75 \mathrm{~min})$ were well resolved.

Limits of detection (between 0.01468 and $0.1319 \mu \mathrm{g} \mathrm{mL}^{-1}$ ) and limits of quantification (between 0.04893 and $0.4395 \mu \mathrm{g} \mathrm{mL}^{-1}$ ) were acceptable. All correlation coefficients for calibration curves gave values not less than 0.9973 (Table 4). Our methodology to determine the phenolic profile of microalgae and cyanobacteria offers adequate sensitivity.

Among cyanobacteria extracts, GA and CA were only identified in Nostoc commune. Phenolic constituents GA, C, E, SA, PA, and CA were not detected in Nostoc sp., Leptolyngbya protospira, Nodularia spumigena, Phormidiochaete sp., Arthrospira platensis, and the strain Caespitella pascheri (Table 5). Klejdus et al. [29] reported that phenolic compounds were more abundant in microalgae compared to cyanobacteria species. These authors related the lack of phenolic compounds in cyanobacteria with the different evolutionary states of microalgae and cyanobacteria, since microalgae are organisms more advanced with phenolic compounds involved in several stress adaptation mechanisms [22, 23, 29]. However, several reports have demonstrated that cyanobacteria produce a great variety of secondary bioactive metabolites [40, 41]. 


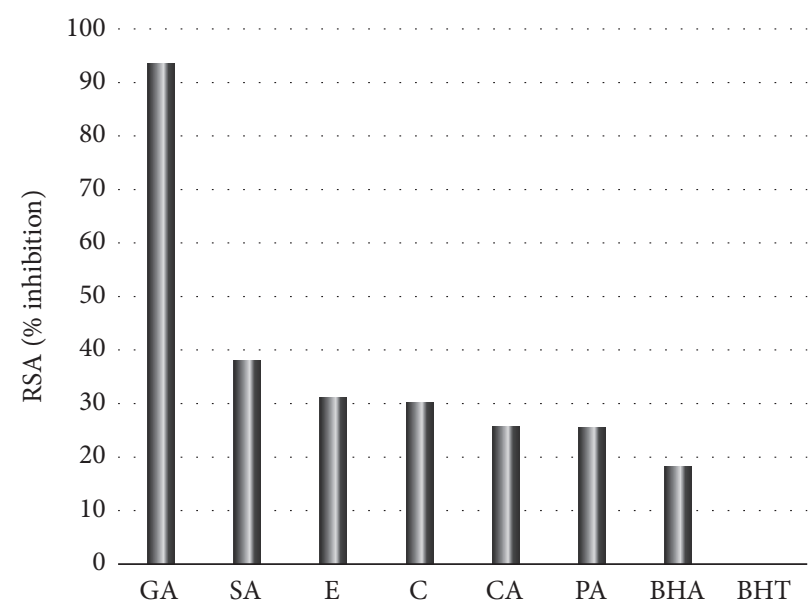

FIGURE 1: Relative radical scavenging activity (RSA) of pure phenolic compounds solutions at $0.1 \mathrm{mg} \mathrm{mL}^{-1}$.

Among all tested microalgae, Caespitella pascheri did not show phenolic compounds. However, GA was identified in Spirogyra sp. and PA was detected in Ankistrodesmus sp. The extract derived from Euglena cantabrica exhibited the highest amount of GA and PA in comparison with the other strains in the present study $(5,872$ and $2,970 \mu$ g per gram of freeze-dried material, resp.) and also presented relevant quantities of compounds C, CA, and E (Table 5). The results here agree with recently published studies focused on the macroalgae Himanthalia elongata (Ochrophyta) which have shown relevant amounts of phenolic compounds increased to levels of mg per gram of freeze-dried algae [42], which seems to be common in many macroalgae species [43]. These contents of phenolic compounds are significantly higher compared to other previously published data $[29,30]$. Onofrejová et al. [30] reported lower amounts of phenolic compounds extracted from in vitro culture of the microalgae Spongiochloris spongiosa $\left(5.1 \mu \mathrm{g} \mathrm{g}^{-1}\right)$ and the cyanobacteria Anabaena doliolum $\left(3.6 \mu \mathrm{gg}^{-1}\right)$ and from food products including marine macroalgae Undaria pinnatifida (Wakame) and Porphyra tenera (Nori) (1.0 and $1.9 \mu \mathrm{g} \mathrm{g}^{-1}$, resp.). Strains Spirogyra sp. and Ankistrodesmus sp. also showed higher contents of phenolic compounds (91.4 and $25.4 \mu \mathrm{g} \mathrm{g}^{-1}$, resp.) compared to data for Nori and Wakame. Klejdus et al. [29] reported that Spongiochloris spongiosa, Spirulina platensis, Anabaena doliolum, Nostoc sp., and Cylindrospermum sp. contained phenolic compounds at $\mu \mathrm{g}$ levels per gram of biomass. These findings concord well with results in previous studies in our laboratory, where high contents of several phenolic compounds such as gentisic acid and (+) catechin were identified and quantified in the microalgae Dunaliella tertiolecta and Phaeodactylum tricornutum [22, 23].

As can be observed in Figure 1, GA is the most active compound in inhibiting DPPH radical, much more than the synthetic antioxidants BHA and BHT at the same concentration $\left(0.1 \mathrm{mg} \mathrm{mL}^{-1}\right)$. Crude algae extracts consist of a wide variety of substances with active components at lower levels and with interfering constituents that decrease the antioxidant capacity $[44,45]$. Therefore, antioxidant activities determined for some of the cyanobacteria strains and the eukaryotic Caespitella pascheri (Table 3) seem not to be related to their phenolic composition. However, the high content of GA and PA in Euglena cantabrica extracts may explain the radical scavenging activity observed when the extracts were prepared at the same concentration $\left(1 \mathrm{mg} \mathrm{mL}^{-1}\right)$ as pure compounds BHA and BHT.

\section{Conclusion}

Results in this study confirmed that several cyanobacteria and microalgae were effective as scavengers of free radicals and this activity might be related to the phenolics compounds detected in some of the strains. Particularly, Euglena cantabrica displayed relevant quantities of phenolic compounds (gallic acid, protocatechuic acid, (+) catechin, chlorogenic acid, and (-) epicatechin) presenting a significantly high antioxidant capacity that could be considered interesting for different industrial applications. Further studies with a broader selection of microalgae and cyanobacteria and a variety of phenolic compounds are required to confirm new possibilities as those shown for the strains assayed here.

\section{Additional Points}

Practical Applications. Few investigations have focused on the quantification of phenolic compounds in microalgae and their potential application in food preservation to prolong the shelf-life by reducing oxidative deterioration and to improve the textural and sensory properties. On the other hand, diets rich in antioxidants have been long recommended to reduce the incidence of diseases caused by oxidative stress. The euglenoid Euglena cantabrica showed relevant amounts of gallic and protocatechuic acids at mg levels per g DW and a significant antioxidant activity probably due to the presence of the high contents of phenolics.

\section{Conflicts of Interest}

The authors declare that they have no conflicts of interest. 


\section{Acknowledgments}

The authors would like to express their gratitude to Jose Juan Santana for allowing us to use the RP-HPLC equipment. Technical personnel at the Spanish Bank of Algae are acknowledged by maintenance and culture of algal material. This research was supported by the sponsors "Familia Megías Martínez" and "Satocán Group" of the Innova Program 2020 (Fundación Universitaria de Las Palmas).

\section{References}

[1] H. Zhang and R. Tsao, "Dietary polyphenols, oxidative stress and antioxidant and anti-inflammatory effects," Current Opinion in Food Science, vol. 8, pp. 33-42, 2016.

[2] J. E. Klaunig and L. M. Kamendulis, "The role of oxidative stress in carcinogenesis," Annual Review of Pharmacology and Toxicology, vol. 44, pp. 239-267, 2004.

[3] A. Nunomura, R. J. Castellani, X. Zhu, P. I. Moreira, G. Perry, and M. A. Smith, "Involvement of oxidative stress in Alzheimer disease," Journal of Neuropathology and Experimental Neurology, vol. 65, no. 7, pp. 631-641, 2006.

[4] A. Wood-Kaczmar, S. Gandhi, and N. W. Wood, "Understanding the molecular causes of Parkinson's disease," Trends in Molecular Medicine, vol. 12, no. 11, pp. 521-528, 2006.

[5] H. N. Siti, Y. Kamisah, and J. Kamsiah, "The role of oxidative stress, antioxidants and vascular inflammation in cardiovascular disease (a review)," Vascular Pharmacology, vol. 71, pp. 4056, 2015.

[6] J. Dai and R. J. Mumper, "Plant phenolics: extraction, analysis and their antioxidant and anticancer properties," Molecules, vol. 15, no. 10, pp. 7313-7352, 2010.

[7] K. B. Pandey and S. I. Rizvi, "Plant polyphenols as dietary antioxidants in human health and disease," Oxidative Medicine and Cellular Longevity, vol. 2, no. 5, pp. 270-278, 2009.

[8] K. Jomova and M. Valko, "Importance of iron chelation in free radical-induced oxidative stress and human disease," Current Pharmaceutical Design, vol. 17, no. 31, pp. 3460-3473, 2011.

[9] S. Quideau, D. Deffieux, C. Douat-Casassus, and L. Pouységu, "Plant polyphenols: chemical properties, biological activities, and synthesis," Angewandte Chemie-International Edition, vol. 50, no. 3, pp. 586-621, 2011.

[10] F. Shahidi and Y. Zhong, "Novel antioxidants in food quality preservation and health promotion," European Journal of Lipid Science and Technology, vol. 112, no. 9, pp. 930-940, 2010.

[11] Y. Athukorala, K.-W. Lee, E.-J. Park et al., "Reduction of lipid peroxidation and $\mathrm{H}_{2} \mathrm{O}_{2}$-mediated DNA damage by a red alga (Grateloupia filicina) methanolic extract," Journal of the Science of Food and Agriculture, vol. 85, no. 14, pp. 2341-2348, 2005.

[12] S. Cox and N. Abu-Ghannam, "Incorporation of himanthalia elongata seaweed to enhance the phytochemical content of breadsticks using response surface methodology (RSM)," International Food Research Journal, vol. 20, no. 4, pp. 1537-1545, 2013.

[13] R. E. Cian, M. S. Caballero, N. Sabbag, R. J. González, and S. R. Drago, "Bio-accessibility of bioactive compounds (ACE inhibitors and antioxidants) from extruded maize products added with a red seaweed Porphyra columbina," LWT_Food Science and Technology, vol. 55, no. 1, pp. 51-58, 2014.

[14] I. López-López, S. Bastida, C. Ruiz-Capillas et al., "Composition and antioxidant capacity of low-salt meat emulsion model systems containing edible seaweeds," Meat Science, vol. 83, no. 3, pp. 492-498, 2009.

[15] J. Ortiz, J. P. Vivanco, and S. P. Aubourg, "Lipid and sensory quality of canned Atlantic salmon (Salmo salar): effect of the use of different seaweed extracts as covering liquids," European Journal of Lipid Science and Technology, vol. 116, no. 5, pp. 596605, 2014.

[16] E. Rodríguez De Marco, M. E. Steffolani, C. S. Martínez, and A. E. León, "Effects of spirulina biomass on the technological and nutritional quality of bread wheat pasta," LWT-Food Science and Technology, vol. 58, no. 1, pp. 102-108, 2014.

[17] T. L. Chacón-Lee and G. E. González-Mariño, "Microalgae for "healthy" foods-possibilities and challenges," Comprehensive Reviews in Food Science and Food Safety, vol. 9, no. 6, pp. 655675, 2010.

[18] J. T. Cirulis, J. A. Scott, and G. M. Ross, "Management of oxidative stress by microalgae," Canadian Journal of Physiology and Pharmacology, vol. 91, no. 1, pp. 15-21, 2013.

[19] M. Herrero, L. Jaime, P. J. Martín-Álvarez, A. Cifuentes, and E. Ibáñez, "Optimization of the extraction of antioxidants from Dunaliella salina microalga by pressurized liquids," Journal of Agricultural and Food Chemistry, vol. 54, no. 15, pp. 5597-5603, 2006.

[20] H. Safafar, J. van Wagenen, P. Møller, and C. Jacobsen, "Carotenoids, phenolic compounds and tocopherols contribute to the antioxidative properties of some microalgae species grown on industrial wastewater," Marine Drugs, vol. 13, no. 12, pp. 73397356, 2015.

[21] M. I. Heller, K. Wuttig, and P. L. Croot, "Identifying the sources and sinks of CDOM/FDOM across the mauritanian shelf and their potential role in the decomposition of superoxide $\left(\mathrm{O}_{2}^{-}\right)$," Frontiers in Marine Science, vol. 3, article 132, 2016.

[22] A. López, M. Rico, J. M. Santana-Casiano, A. G. González, and M. González-Dávila, "Phenolic profile of Dunaliella tertiolecta growing under high levels of copper and iron," Environmental Science and Pollution Research, vol. 22, no. 19, pp. 14820-14828, 2015.

[23] M. Rico, A. López, J. M. Santana-Casiano, A. G. González, and M. González-Dávila, "Variability of the phenolic profile in the diatom Phaeodactylum tricornutum growing under copper and iron stress," Limnology and Oceanography, vol. 58, no. 1, pp. 144$152,2013$.

[24] H.-B. Li, K.-W. Cheng, C.-C. Wong, K.-W. Fan, F. Chen, and Y. Jiang, "Evaluation of antioxidant capacity and total phenolic content of different fractions of selected microalgae," Food Chemistry, vol. 102, no. 3, pp. 771-776, 2007.

[25] A. R. Rao, R. Sarada, V. Baskaran, and G. A. Ravishankar, "Antioxidant activity of Botryococcus braunii extract elucidated in vitro models," Journal of Agricultural and Food Chemistry, vol. 54, no. 13, pp. 4593-4599, 2006.

[26] R. Krachler, F. Von Der Kammer, F. Jirsa et al., "Nanoscale lignin particles as sources of dissolved iron to the ocean," Global Biogeochemical Cycles, vol. 26, no. 3, Article ID GB3024, 2012.

[27] E. B. Kujawinski, K. Longnecker, N. V. Blough et al., "Identification of possible source markers in marine dissolved organic matter using ultrahigh resolution mass spectrometry," Geochimica et Cosmochimica Acta, vol. 73, no. 15, pp. 4384-4399, 2009.

[28] P. G. Waterman and S. Mole, Analysis of Phenolic Plant Metabolites, Blackwell Publishing, Oxford, UK, 1994.

[29] B. Klejdus, J. Kopecký, L. Benešová, and J. Vacek, "Solidphase/supercritical-fluid extraction for liquid chromatography 
of phenolic compounds in freshwater microalgae and selected cyanobacterial species," Journal of Chromatography A, vol. 1216, no. 5, pp. 763-771, 2009.

[30] L. Onofrejová, J. Vašíčková, B. Klejdus et al., "Bioactive phenols in algae: the application of pressurized-liquid and solid-phase extraction techniques," Journal of Pharmaceutical and Biomedical Analysis, vol. 51, no. 2, pp. 464-470, 2010.

[31] T. Shibata, Y. Hama, T. Miyasaki, M. Ito, and T. Nakamura, "Extracellular secretion of phenolic substances from living brown algae," Journal of Applied Phycology, vol. 18, no. 6, pp. 787-794, 2006.

[32] O. I. Aruoma, "Methodological considerations for characterizing potential antioxidant actions of bioactive components in plant foods," Mutation Research/Fundamental and Molecular Mechanisms of Mutagenesis, vol. 523-524, pp. 9-20, 2003.

[33] I. Rodríguez-García and J. L. Guil-Guerrero, "Evaluation of the antioxidant activity of three microalgal species for use as dietary supplements and in the preservation of foods," Food Chemistry, vol. 108, no. 3, pp. 1023-1026, 2008.

[34] A. López, M. Rico, A. Rivero, and M. Suárez de Tangil, “The effects of solvents on the phenolic contents and antioxidant activity of Stypocaulon scoparium algae extracts," Food Chemistry, vol. 125, no. 3, pp. 1104-1109, 2011.

[35] T. M. Rababah, K. I. Ereifej, R. B. Esoh, M. H. Al-u'datt, M. A. Alrababah, and W. Yang, "Antioxidant activities, total phenolics and HPLC analyses of the phenolic compounds of extracts from common Mediterranean plants," Natural Product Research, vol. 25, no. 6, pp. 596-605, 2011.

[36] C. Guo, G. Cao, E. Sofic, and R. L. Prior, "High-performance liquid chromatography coupled with coulometric array detection of electroactive components in fruits and vegetables: relationship to oxygen radical absorbance capacity," Journal of Agricultural and Food Chemistry, vol. 45, no. 5, pp. 1787-1796, 1997.

[37] E. A. Hayouni, M. Abedrabba, M. Bouix, and M. Hamdi, "The effects of solvents and extraction method on the phenolic contents and biological activities in vitro of Tunisian Quercus coccifera L. and Juniperus phoenicea L. fruit extracts," Food Chemistry, vol. 105, no. 3, pp. 1126-1134, 2007.

[38] T. Kuda, M. Tsunekawa, H. Goto, and Y. Araki, "Antioxidant properties of four edible algae harvested in the Noto Peninsula, Japan," Journal of Food Composition and Analysis, vol. 18, no. 7, pp. 625-633, 2005.

[39] A. Maadane, N. Merghoub, T. Ainane et al., "Antioxidant activity of some Moroccan marine microalgae: pufa profiles, carotenoids and phenolic content," Journal of Biotechnology, vol. 215, pp. 13-19, 2015.

[40] M. Plaza, M. Herrero, A. Alejandro Cifuentes, and E. Ibáñez, "Innovative natural functional ingredients from microalgae," Journal of Agricultural and Food Chemistry, vol. 57, no. 16, pp. 7159-7170, 2009.

[41] E. A. Shalaby, "Algae as promising organisms for environment and health," Plant Signaling and Behavior, vol. 6, no. 9, pp. 13381350, 2011.

[42] M. Belda, D. Sanchez, E. Bover et al., "Extraction of polyphenols in Himanthalia elongata and determination by high performance liquid chromatography with diode array detector prior to its potential use against oxidative stress," Journal of Chromatography B, vol. 1033-1034, pp. 334-341, 2016.

[43] W.-W. Zhang, X.-J. Duan, H.-L. Huang, Y. Zhang, and B.-G. Wang, "Evaluation of 28 marine algae from the Qingdao coast for antioxidative capacity and determination of antioxidant efficiency and total phenolic content of fractions and subfractions derived from Symphyocladia latiuscula (Rhodomelaceae)," Journal of Applied Phycology, vol. 19, no. 2, pp. 97-108, 2007.

[44] H. Chernane, M. Mansori, S. Latique, and M. El Kaoua, "Evaluation of antioxidant capacity of methanol extract and its solvent fractions obtained from four moroccan macro algae species," European Scientific Journal, vol. 10, no. 15, pp. 35-48, 2014.

[45] A. Tariq, M. Athar, J. Ara, V. Sultana, S. Ehteshamul-Haque, and M. Ahmad, "Biochemical evaluation of antioxidant activity in extracts and polysaccharide fractions of seaweeds," Global Journal of Environmental Science and Management, vol. 1, no. 1, pp. 47-62, 2015. 

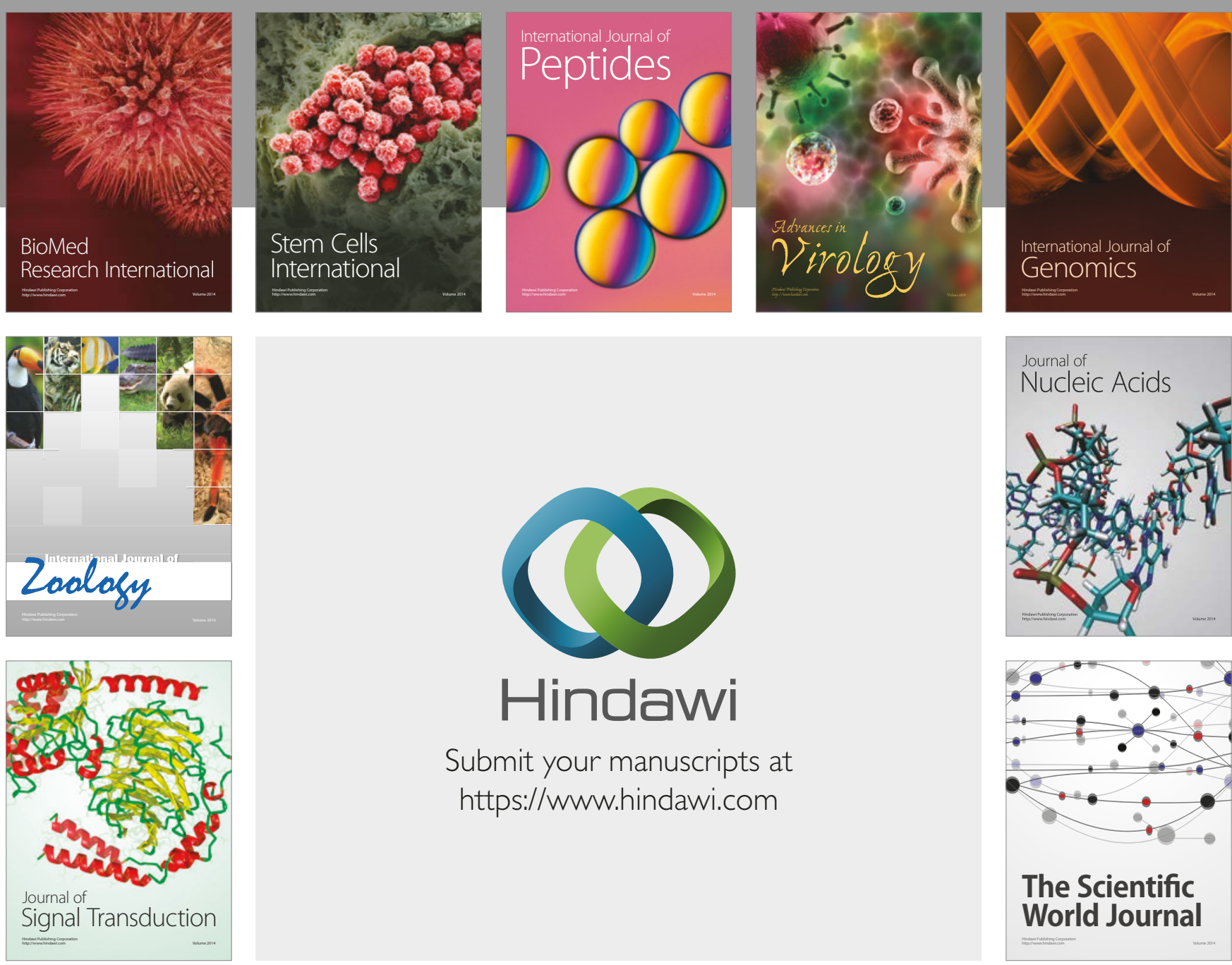

Submit your manuscripts at

https://www.hindawi.com
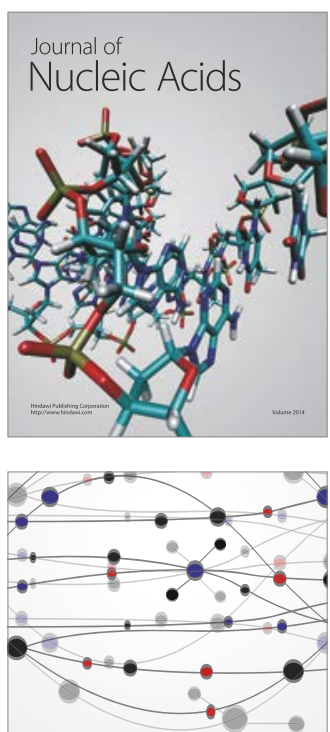

The Scientific World Journal

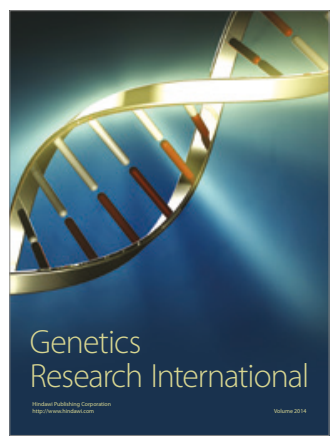

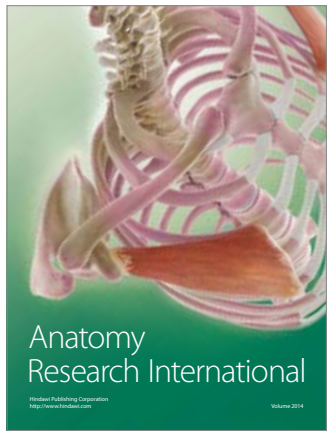

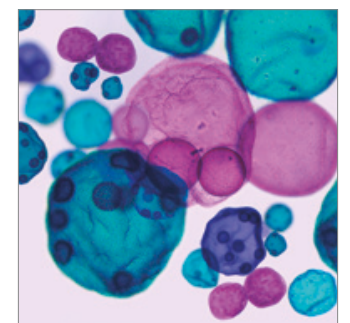

International Journal of Microbiology
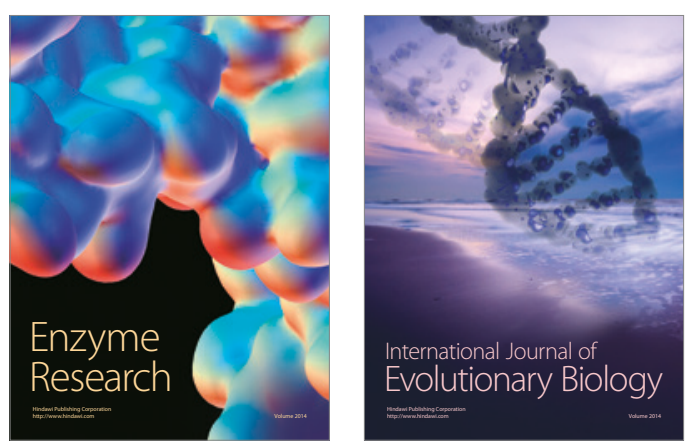
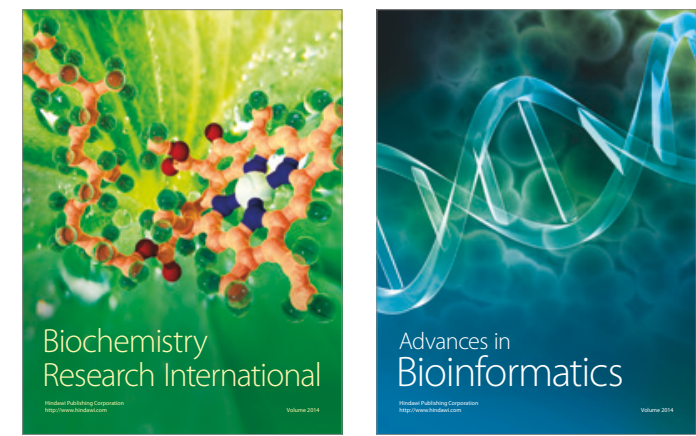

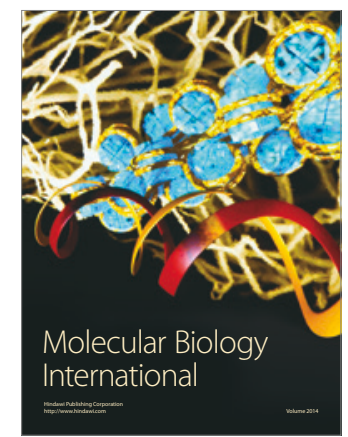

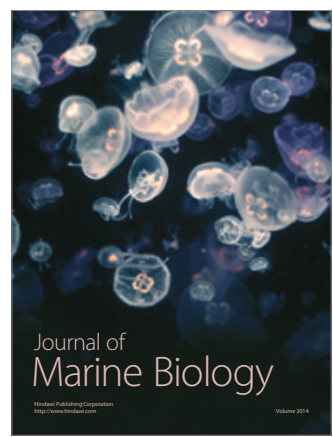

